Article

\title{
Transient Voltage UWB Online Monitoring System for Insulation Failure Analysis and Fault Location of GIL ${ }^{\dagger}$
}

\author{
Ziwei Zhang ${ }^{1}{ }^{\mathbb{D}}$, Dengwei Ding ${ }^{1}$, Liang He ${ }^{1}$, Weidong Liu ${ }^{1}$, Cuifen Bai ${ }^{2}{ }^{*}$ and Junjun Liu ${ }^{3}$ \\ 1 Sichuan Energy Internet Research Institute, Tsinghua University, Chengdu 610213, China; \\ ziwei.z@outlook.com (Z.Z.); sunnyall123@163.com (D.D.); helxjtu@163.com (L.H.); \\ lwd-dea@mail.tsinghua.edu.cn (W.L.) \\ 2 Hebei Key Laboratory of Safety Monitoring and Mining Equipment, North China Institute of Science and \\ Technology, Langfang 065201, China \\ 3 Maintenance Center, State Grid Chengdu Power Supply Company, Chengdu 610041, China; \\ liujj1696@sc.sgcc.com.cn \\ * Correspondence: cuifenbai@163.com \\ + This paper is an extended version of our paper published in 2020 IEEE International Conference on High \\ Voltage Engineering and Application (ICHVE), Beijing, China, 6-10 September 2020.
}

Citation: Zhang, Z.; Ding, D.; He, L.; Liu, W.; Bai, C.; Liu, J. Transient Voltage UWB Online Monitoring System for Insulation Failure Analysis and Fault Location of GIL. Energies 2021, 14, 4863.

https://doi.org/10.3390/en14164863

Academic Editor: Pawel Rozga

Received: 5 July 2021

Accepted: 4 August 2021

Published: 9 August 2021

Publisher's Note: MDPI stays neutral with regard to jurisdictional claims in published maps and institutional affiliations.

Copyright: (c) 2021 by the authors. Licensee MDPI, Basel, Switzerland. This article is an open access article distributed under the terms and conditions of the Creative Commons Attribution (CC BY) license (https:// creativecommons.org/licenses/by/ $4.0 /)$.

\begin{abstract}
Transient voltage generated in ultra-high voltage (UHV) transmission system has a severe impact on the insulation state of gas-insulated transmission lines (GIL). In order to monitor the transient voltage process occurring in UHV GIL during operation, this paper constructs a transient voltage ultra-wideband (UWB) online monitoring system based on capacitive voltage division. This system has been applied in an 1100 kilovolt $(\mathrm{kV})$ GIL utility tunnel project. It can be used to analyze the characteristics of the recorded transient voltage waveforms for distinguishing different types of insulation failure. In this paper, through the case studies in time domain and time-frequency domain, the case of $\mathrm{SF}_{6}$ gap breakdown and that of post insulator flashover have differentiated characteristics in instantaneous frequency. Additionally, a case of secondary discharge is successfully estimated through the time-frequency distribution of the transient voltage. In order to find the malfunctioning chamber of GIL rapidly, a two-terminal TW-based fault location method based on this monitoring system is developed in this paper. The case study validates the locating accuracy which directly support for shortening the maintenance time of GIL.
\end{abstract}

Keywords: UHV GIL; transient voltage; on-line monitoring system; UWB voltage sensing

\section{Introduction}

In order to raise the efficiency of clean energy and reduce the coal consumption, a power transmission system with large capacity is necessary to deliver electricity from the renewable resource-rich areas to the areas with high electricity consumption [1]. Ultra-high voltage (UHV) gas-insulated transmission lines (GIL) are an excellent technology for a high-power underground transmission system with long delivering distances and low energy losses [2]. A general structure of GIL consists of two concentric aluminum tubes $[3,4]$. The inner tube is the conductor with high current-carrying capability, and the outer aluminum enclosure offers a mechanical and electromagnetic encapsulation [5-7]. The conductor is held in the center of the enclosure by using basin-type insulators and post insulators. A gas mixture of nitrogen $\left(\mathrm{N}_{2}\right)$ and sulfur hexafluoride $\left(\mathrm{SF}_{6}\right)$ is filled in the tubes as insulating medium [8,9]. Usually, a UHV power transmission system is constructed across every long distance, and overhead transmission lines cannot be built in some circumstances, such as crossing a wide river, a mountain or metropolitan areas [10]. Thus, the GIL technology is tending to be used as an underground solution for UHV transmission systems. Moreover, due to the advantage of space saving, the GIL technology is widely used to connect large-scale hydropower plants or nuclear power plants to the 
public transmission grid [11]. In recent years, an 1100 kilovolt (kV) GIL project is built under the Yangtze River to transmit clean energy from west to east China.

The operating reliability of GIL is directly related to the security and stability of the power system. In highly intensive electric field inside UHV GIL, latent insulation defects are prone to occur on the insulators, because insulators of UHV GIL require enhanced dielectric strength and more critical manufacturing techniques [12,13]. Additionally, any scratching or dislocation of installation during transportation and installation of GIL could lead to latent dangers, such as electrode surface defects, insulator cracking and left inside small metal particles [14-16]. These latent dangers inside GIL possibly lead to insulation breakdown in the process of voltage withstand test or normal operation $[17,18]$. For on-site test of $1100 \mathrm{kV} \mathrm{GIL}$, the power frequency withstand voltage is $1100 \mathrm{kV}$ (r.m.s. value), and the lightning impulse withstand voltage is $2400 \mathrm{kV}$ (peak value). Once a breakdown occurs in GIL, transient voltage with steep change will be excited [17]. The transient voltage will travel back and forth between the fault point and the port of the bushing, forming the typical traveling wave (TW) process. Due to small resistance of GIL, the TW energy cannot vanish quickly. The attenuation of transient voltage will slow down, which will threaten to the insulation of other parts of GIL equipment. Therefore, it is important to interpret the characteristics of transient voltage traveling inside UHV GIL.

In previous research, the characteristics of transient voltage traveling inside UHV GIL are usually studied by simulation. However, the simulation results have limited support for practical engineering applications. Capturing accurate transient voltage in real operating GIL offers an alternative way to study the characteristics of transient voltage traveling inside long-distance UHV GIL [2]. Furthermore, in order to minimize the impact of outage, once a breakdown occurs in GIL, it is necessary to quickly and accurately locate the discharge location [19]. A gas chamber of UHV GIL is typically $20 \mathrm{~m}$, so the accuracy of the fault location technique should keep within $20 \mathrm{~m}$ to recognize the malfunctioning chamber. Previous research on TW-based fault location technology is mostly aimed at conventional overhead lines and cables [20,21]. The accuracy is around $300 \mathrm{~m}$ (a typical tower span), which is difficult to meet the requirements of the fault location for UHV GIL [22].

This paper presents a novel structure of a transient voltage on-line monitoring system based on ultra-wideband (UWB) capacitive voltage sensor. This system is applied in an $1100 \mathrm{kV}$ GIL project. Depending on this on-line monitoring system, a fault location method that can satisfy the required precision of UHV GIL is developed. This method is simple to automatically implement with respect to rapidly locating the malfunctioning chamber of typical UHV GIL. Two real-world cases of insulation breakdown happened in the GIL project are recorded by this monitoring system and delivered in this application paper. Relying on these two insulation failure cases that occurred in dielectric withstand voltage test and actual operation respectively, the time-frequency distributions of transient voltage excited in a real UHV GIL is investigated in discussion. Additionally, in the case of insulation flashover during operation, the fault location method is implemented in practice to validate the accuracy of fast fault locating function of this system.

\section{Materials and Methods}

\subsection{Construction of Transient Voltage UWB Online Monitoring System}

As a part of the Huainan-Nanjing-Shanghai $1000 \mathrm{kV}$ alternating current (AC) power transmission system, the $1100 \mathrm{kV}$ Sutong GIL utility tunnel laid under the Yangtze River measured $5.4 \mathrm{~km}$ long and $75 \mathrm{~m}$ deep [23,24]. This project is a worldwide breakthrough for UHV GIL technology with the longest distance, the highest voltage level and the largest transmission capacity. The transient voltage online monitoring system with ultra-wide bandwidth is designed innovatively and applied in this project. The structure of this monitoring system is shown in Figure 1. In this system, transient voltage measurement points are set at the ports of bushings which are located at both ends of each phase of 
the GIL tunnel. As illustrated in Figure 1, the system is divided into three levels: voltage sensor, monitoring terminal, and storage control unit.

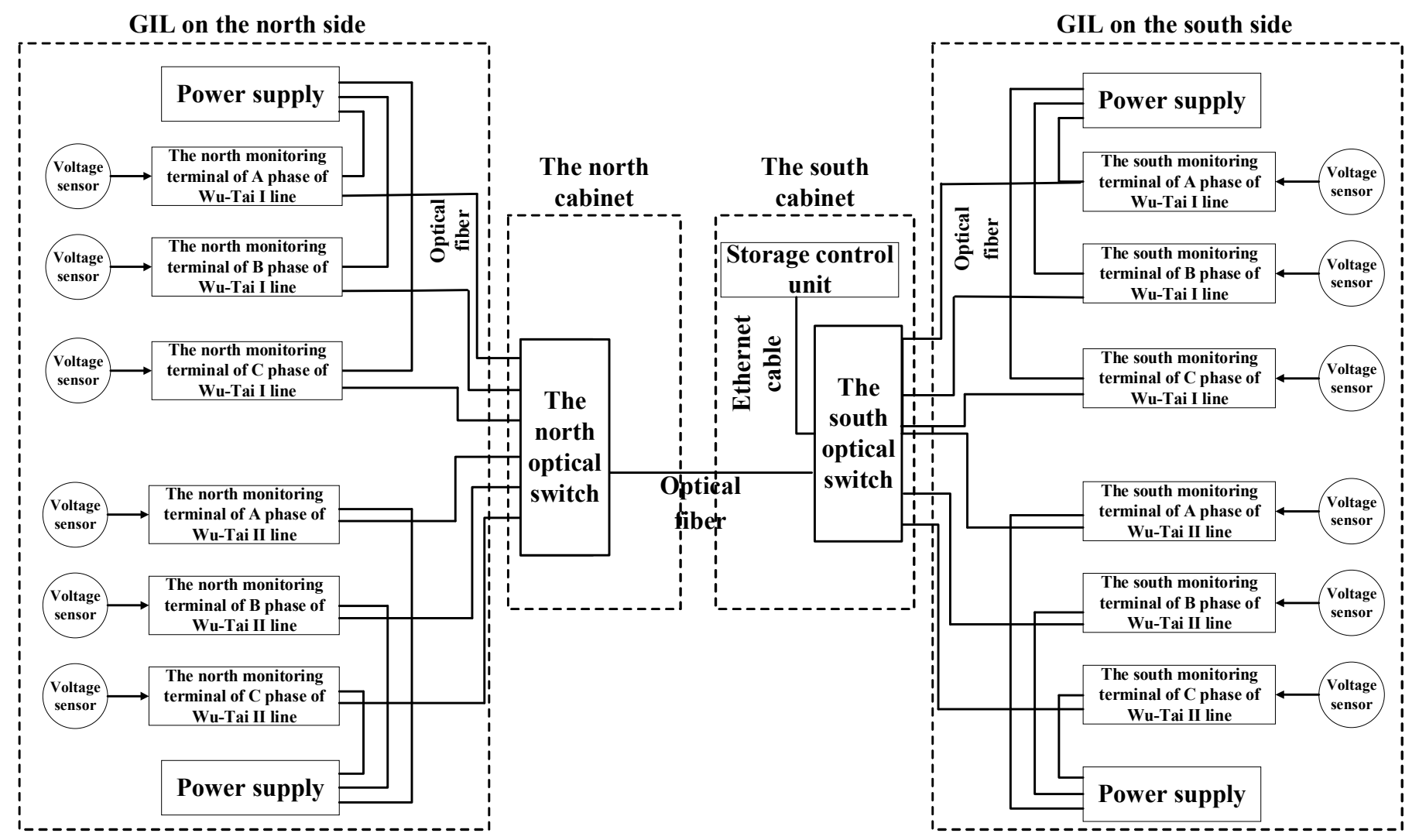

Figure 1. Structure diagram of transient voltage UWB online monitoring system for $1100 \mathrm{kV}$ Sutong GIL project.

\subsubsection{Ultra-Wideband Voltage Sensor}

The UWB voltage sensor is used to measure the voltage in an expected frequency range. The principle is based on the theory of capacitive voltage division. Its basic components include hand hole cover plate, induction electrode and insulating film, as described in Figure 2a. The original cover plate on the GIL is modified to install this voltage sensor. As shown in Figure 2b, the induction electrode is installed inside the hand hole of the GIL, and a bespoke shield cover is added to control the electric field distribution around the induction electrode. The structural parameters of voltage sensors are estimated according to the detailed structure of the hand hole by finite element method (FEM). In this system, a shield plate with $110 \mathrm{~mm}$ inner diameter and the $83 \mathrm{~mm}$ height is also fabricated to achieve an ideal voltage division ratio. In this case, the voltage division ratio is about $1,360,000$.

The induction electrode is installed in the shield cover as depicted in Figure 2 a. The induction electrode is a cylinder with $100 \mathrm{~mm}$ diameter and $20 \mathrm{~mm}$ thickness. Teflon film with $100 \mu \mathrm{m}$ thickness is chosen as the insulating medium between the electrode and the hand hole cover plate [25]. The electrode and the high-voltage conductor constitute the high-voltage arm capacitance of $0.001 \mathrm{pF}$ level, and the electrode and the cover plate constitute the low-voltage arm capacitance of $\mathrm{nF}$ level. The effective bandwidth of the voltage sensor is verified at $2.1 \mathrm{~Hz} \sim 230 \mathrm{MHz}$ calibrated by a standard resistance divider in the calibration experiment. 


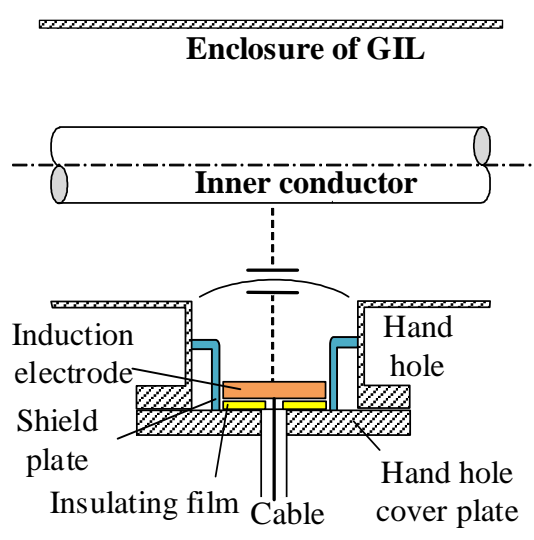

(a)

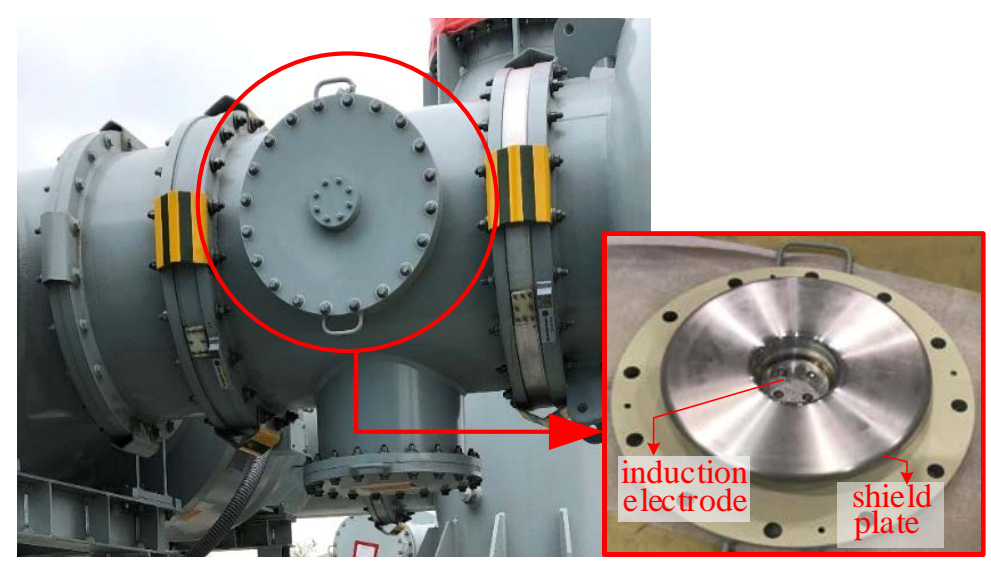

(b)

Figure 2. Ultra-wideband voltage sensor. (a) Schematic structure of the voltage sensor; (b) entity of voltage sensor and its installation position.

\subsubsection{Monitoring Terminal}

A monitoring terminal includes an impedance conversion unit, a high-speed acquisition unit, a power module, an isolation transformer, a GPS module and an antenna. Figure 3a shows the schematic structure. Except for the antenna, other modules are installed in stainless steel shielding box, which provides $220 \mathrm{~V}$ AC power supply externally. Through an isolation transformer, the power module converts the AC power into DC power for acquisition unit and impedance conversion unit.

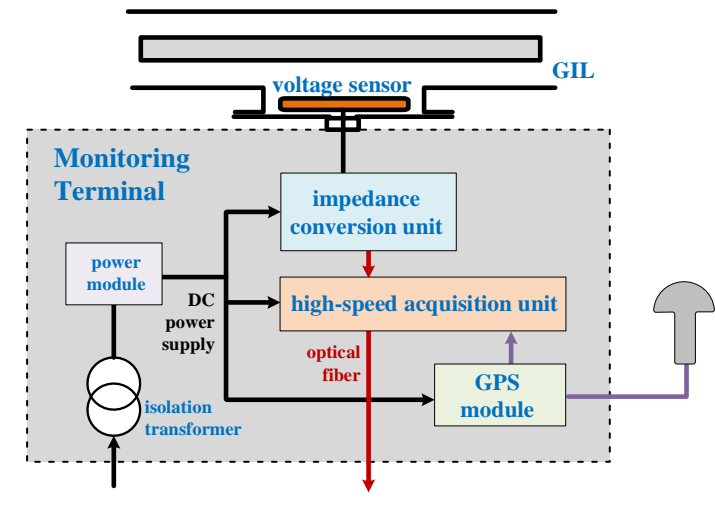

(a)

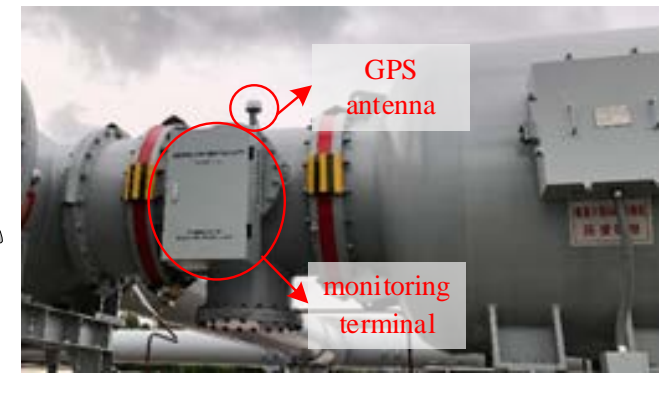

(b)

Figure 3. Monitoring terminal. (a) Structure of the monitoring terminal; (b) Entity of monitoring terminal and its installation position.

To ensure a sufficient measuring accuracy of power frequency voltage, an impedance conversion circuit is added at the output of the low-voltage arm capacitance. The input resistance of the impedance conversion circuit is set at giga- $\Omega(G \Omega)$ range, so that the low cut-off frequency of the measurement system is expanded sufficiently. The output resistance is set around $0.1 \Omega$ to enhance the driving ability to the acquisition unit. The sampling rate of the data acquisition unit is $250 \mathrm{MS} / \mathrm{s}$, the analog bandwidth is $100 \mathrm{MHz}$. The acquisition unit supports First Input First Output (FIFO) mode of continuous acquisition and storage. Additionally, the acquisition unit supports gradient triggering mode. When a sudden change in monitoring voltage exceeds the presupposed gradient value, the acquisition unit will be triggered for long-term recording. The monitoring terminal is fixed on the flange outside the voltage sensor, as shown in Figure $3 \mathrm{~b}$. 
A GPS module with $10 \mathrm{~ns}$ resolution is applied to meet the requirement of this monitoring system. To ensure the soundness of the power supply for the monitoring terminal, the isolation transformer is used to suppress the interference of ground potential rise caused by the operation of isolation switch and circuit breaker. The insulation withstand voltage of iron core (iron core grounding) between the primary and secondary winding can reach $20 \mathrm{kV}$. The common mode rejection attenuation characteristic curve of the isolation transformer is shown in Figure 4. It can be found that the isolation transformer can greatly restrain the interference signal above $20 \mathrm{kH}$.

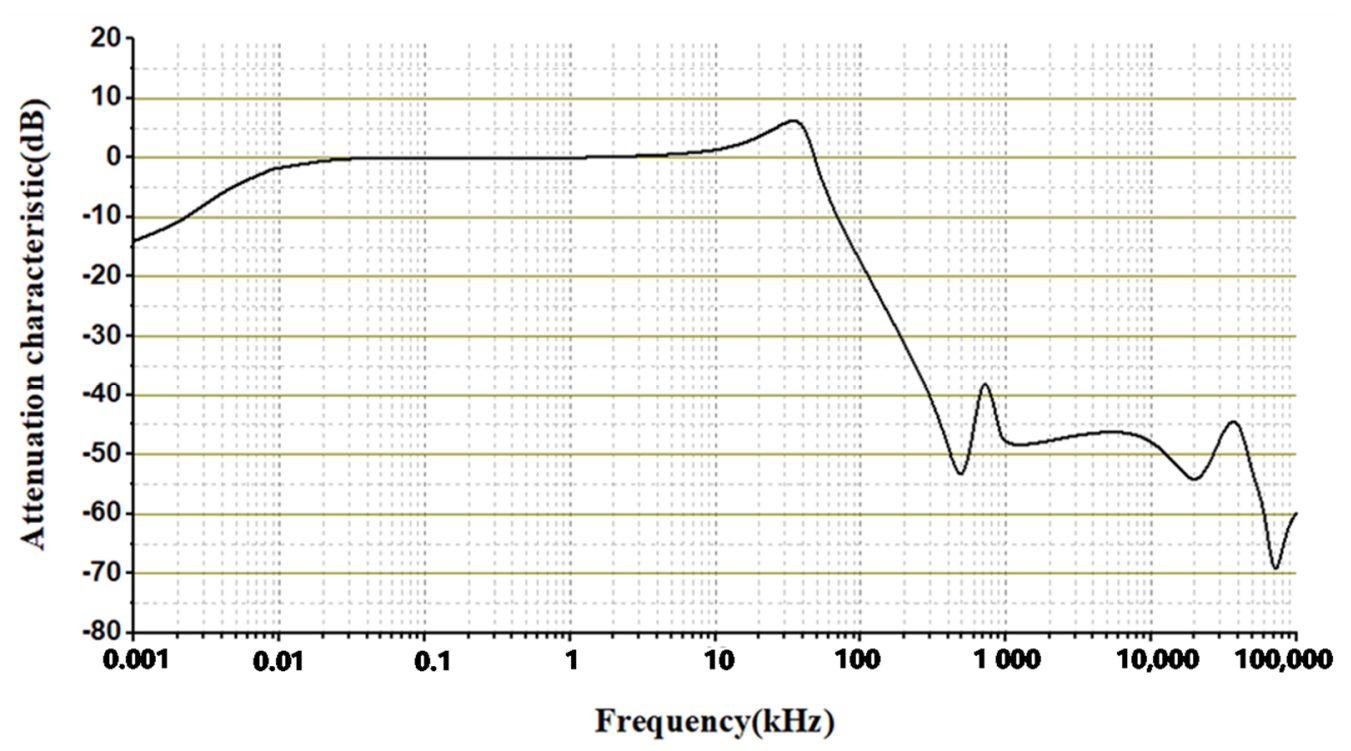

Figure 4. Common-mode suppression attenuation characteristic curve of the isolation transformer.

\subsubsection{Storage Control Unit}

The storage control unit is placed in a cabinet in a relay protection room. It includes an optical switch, control host (server) and other equipment. Twelve monitoring terminals are connected with optical switch through single-mode optical fiber. The basic function of the storage control unit it to store and communicate the transient voltage data. Additionally, an automatic analysis for location of insulation breakdown fault is accomplished relying on the storage control unit. The location accuracy is expected to attain at least $20 \mathrm{~m}$. This analysis function can realize fast location of breakdown point of the operation GIL. The applied fault location method is based on principle of two-terminal TW theory with synchronous UWB measurement of transient voltage.

\subsection{Two-Terminal TW-Based Fault Location for GIL}

TW-based fault location methods have been widely applied for adaptive auto-reclosing, line protection and disturbance diagnosis of transmission lines. It is also applicable for GIL in theory since the transient voltage can be accurately captured by the UWB online monitoring system. The principle of TW-based fault location for GIL is depicted in Figure 5. When an insulation breakdown occurs in GIL, a pair of transient voltage TWs as the same amplitude as the breakdown voltage and opposite polarity will propagate along the GIL in opposite directions. The distance between two UWB voltage sensors which are adjacent to the bushings at the ends of GIL is marked as $L$. The distance between the breakdown position and the sensor $\mathrm{A}$ in the south is denoted as $d$. The moments that the pair of TWs arrive at the installing positions of sensor $\mathrm{A}$ and $\mathrm{B}$ are symbolized as $t_{a}$ and $t_{b}$, respectively. 


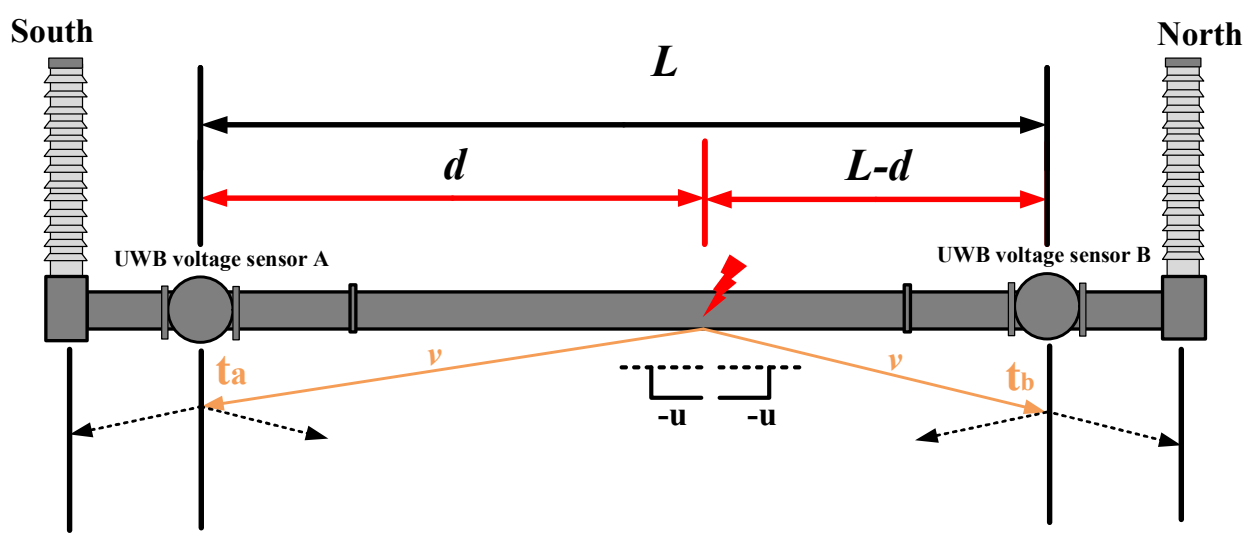

Figure 5. Schematic diagram of two-terminal traveling wave location principle of GIL.

The distance $L$ can be calculated by the following equation:

$$
d=\frac{L+\left(t_{a}-t_{b}\right) v}{2}
$$

where $v$ represents the wave propagation velocity along the GIL. The propagation velocity can be obtained by on-site measurement or calculation based on structural parameters of GIL. The formula is:

$$
v=\frac{\omega}{\beta}=\frac{\omega}{\operatorname{Im}(\sqrt{(R+j \omega L)(G+j \omega C)}},
$$

where $\omega$ is frequency in radians/second of the transient wave. $\beta$ is called phase constant, which is the imaginary part of the propagation constant. $R, L, G$ and $C$ are the line parameters, which represent resistance, inductance, conductance and capacitance per unit length of GIL, respectively.

Regarding the UHV GIL tunnel used in the Sutong project, the manufacturers provide the parameters that $\mathrm{C}$ equals $45 \mathrm{pF} / \mathrm{m}$, L equals $0.26 \mu \mathrm{H} / \mathrm{m}, \mathrm{R}$ equals $3.33 \mu \Omega / \mathrm{m}$ and $\mathrm{G}$ can be neglected. Considering high frequency components of the generated transient voltage, the GIL is a case of low loss line $\left(\frac{R}{\omega L} \ll 1\right.$ and $\left.\frac{G}{\omega C} \ll 1\right)$. Then, Equation (2) can be simplified as:

$$
v \approx \frac{1}{\sqrt{L C}} .
$$

Consequently, the calculated velocity is around $292.4 \mathrm{~m} / \mu \mathrm{s}$ by Equation (3) in the application. Based on three cases of actual breakdown positions during the dielectric withstand voltage tests of this project, the propagation velocity is justified as $292.9 \mathrm{~m} / \mu \mathrm{s}$.

\section{Results}

\subsection{Record of TW during Dielectric Withstand Voltage Test}

During the dielectric withstand voltage test, a case of $\mathrm{SF}_{6}$ gap breakdown was captured by the transient voltage UWB online monitoring system. When the test voltage reached $900 \mathrm{kV}$ (effective value), a phase of GIL broke down. Figure 6 shows the record of the transient voltage waveforms in the north and south measuring points.

Figure 6a shows that the voltage rapidly drops to zero after a short oscillation, and then lasts for nearly $20 \mathrm{~ms}$. After the arc at the fault point was extinguished, the power supply of the test system had not been cut off. A voltage around $300 \mathrm{kV}$ at the test frequency resumed. As shown in Figure 6b, the transient voltage waveforms on both sides last nearly $400 \mu \mathrm{s}$. For the TW measured in the south, half a period of the initial square wave is $28.01 \mu \mathrm{s}$, and the half-wave steep time of this first wave is around $120 \mathrm{~ns}$. After one cycle, the regular transient voltage is distorted, due to external flashover of reactor in the test circuit overlapped with the original voltage traveling wave. For the TW measured in the north, half a period of the initial square wave is $10.38 \mu \mathrm{s}$. After nearly $52 \mu \mathrm{s}$, a new 
traveling wave process appears, half the period is around $1.19 \mu \mathrm{s}$. After $250 \mu \mathrm{s}$, it gradually attenuates to zero. Additionally, this waveform head decreases from $1182 \mathrm{kV}$ to $-1702 \mathrm{kV}$, taking about $180 \mathrm{~ns}$, and the half-wave steep time is about $90 \mathrm{~ns}$.
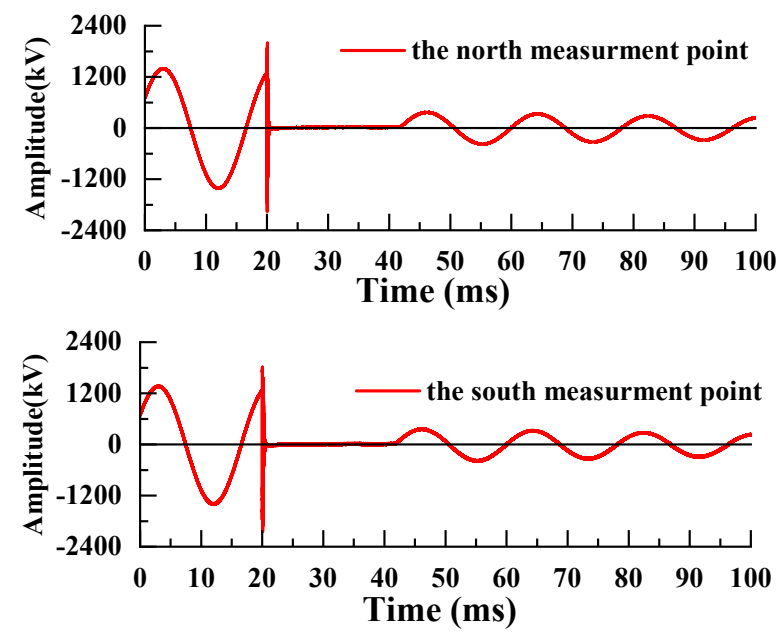

(a)
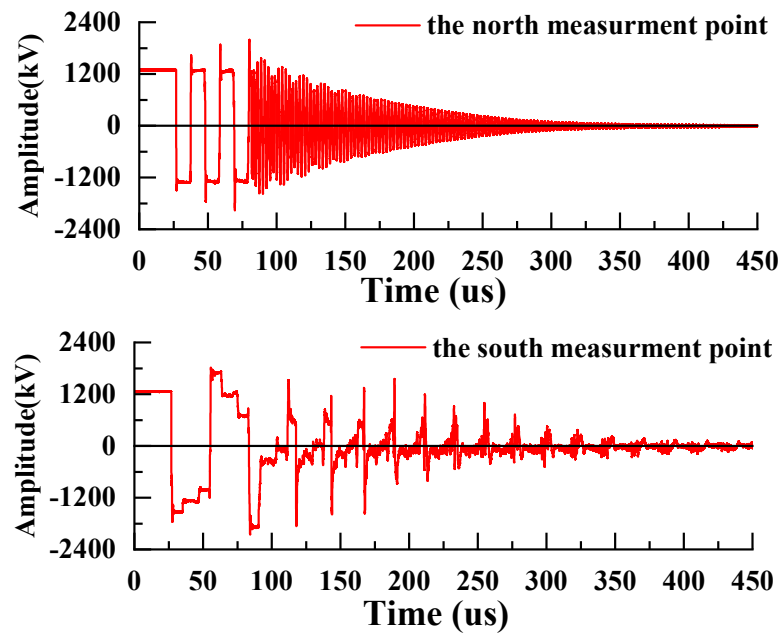

(b)

Figure 6. Transient voltage waveform generated by the $\mathrm{SF}_{6}$ gap breakdown in $1100 \mathrm{kV}$ GIL during dielectric withstand voltage test. (a) Full recorded waveform within $100 \mathrm{~ms}$; (b) an expanded view of the transient waveform.

\subsection{Record of TW during Operation}

A case of internal insulation breakdown was captured in a phase of operating GIL. Figure 7 displays the recorded voltage waveforms of this case. Damped square waves were generated due to refraction and reflection of the travelling wave between the breakdown point and the connection point. For the TW measured in the north, half a period of the initial square wave is around $26.8 \mu \mathrm{s}$, and the half-wave steep time is about $760 \mathrm{~ns}$. For the TW measured in the south, half a period of the initial square wave is around $12.1 \mu \mathrm{s}$, and the half-wave steep time is about $640 \mathrm{~ns}$. Comparing the voltage waveform in Figure 6, the transient voltage caused by GIL insulation flashover during operation jumps much slower.

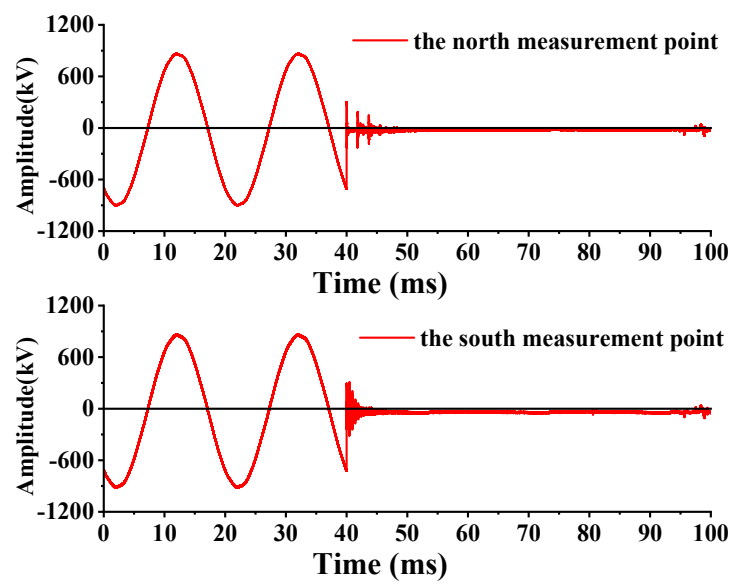

(a)
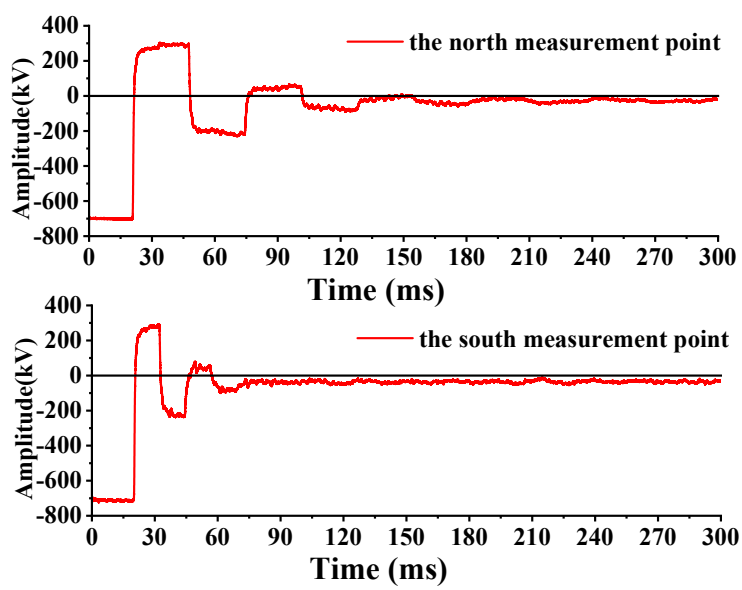

(b)

Figure 7. Transient voltage waveform generated in a phase of operating $1100 \mathrm{kV}$ GIL. (a) Full recorded waveform within $100 \mathrm{~ms}$; (b) an expanded view of the transient waveform. 


\section{Discussion \\ 4.1. Time-Frequency Analysis}

To further investigate the characteristics of the transient voltage excited in different conditions, the transient voltage in time-frequency domain is discussed in this section. The recorded waveforms are transferred by using continuous wavelet transform (CWT) method. Figure 8 shows the time-frequency distributions of $\mathrm{SF}_{6}$ gap breakdown. The instantaneous high-frequency components excited by the voltage mutation are framed.

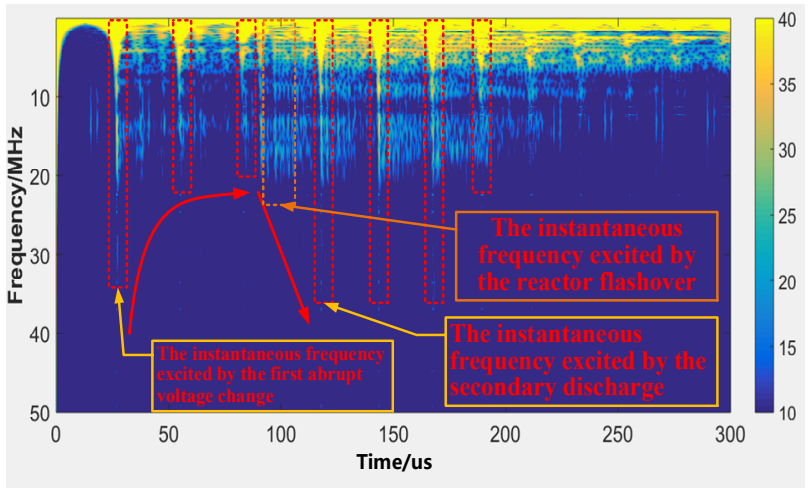

(a)

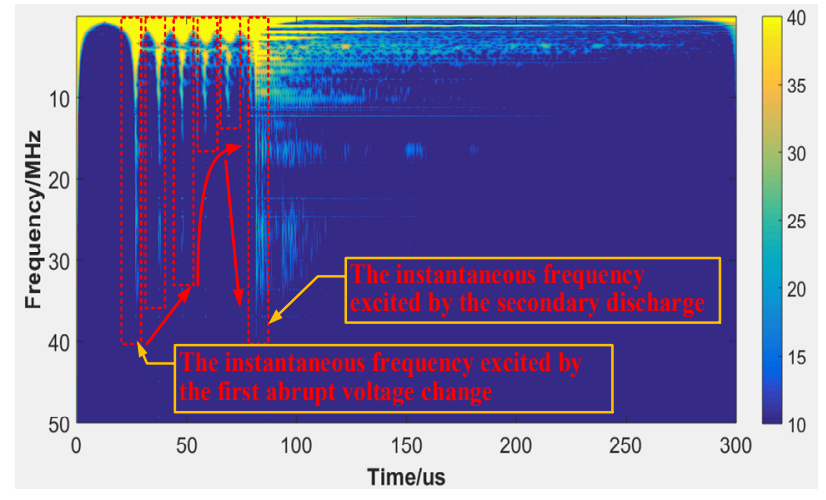

(b)

Figure 8. Time-frequency distributions of the transient voltage excited by $\mathrm{SF}_{6}$ gap breakdown during dielectric withstand voltage test. (a) Spectrum measured by sensor A (south); (b) spectrum measured by sensor B (north).

As illustrated in Figure 8a, the instantaneous frequency of the transient voltage measured in the south is near to $35 \mathrm{MHz}$ at the first abrupt change. The instantaneous frequency component of the next voltage abrupt change appears to be an obvious attenuation. Then, the instantaneous frequency component, which is less than $25 \mathrm{MHz}$, is observed due to a new transient voltage caused by the reactor flashover. Combining the observation of Figures $6 \mathrm{~b}$ and $8 \mathrm{a}$, a high frequency component close to $35 \mathrm{MHz}$ appears again after $75 \mu \mathrm{s}$, and exists in the following two square half-wave periods, and the square half-wave period is shorter at this time. It is speculated that a secondary breakdown happened between the first breakdown point and the end of the south bushing of GIL. In Figure 8b, the instantaneous frequency of the transient voltage measured in the north is close to $35 \mathrm{MHz}$ at the first voltage abrupt change, and then the instantaneous frequency component gradually attenuates. After $52 \mu \mathrm{s}$, a high frequency component with more than $35 \mathrm{MHz}$ appears again. It lasts for nearly $25 \mu \mathrm{s}$ and then decays to less than $10 \mathrm{MHz}$. Similar to on the south side, it indicates that there may be a secondary breakdown between the first breakdown point and the north bushing. During the disassembly inspection, it was found that $\mathrm{SF}_{6}$ gap breakdown occurred between the high voltage conductor and the shell flange at $3460 \mathrm{~m}$, $4110 \mathrm{~m}$ and $5459 \mathrm{~m}$ away from the end of the south bushing. Therefore, it verified the results of the time-frequency analysis above.

Figure 9 presents the time-frequency distributions excited by flashover in a post insulator of an operating GIL. It can be observed that the time-frequency distributions measured at both sides are similar. The instantaneous high frequency component excited by the first voltage sudden change is close to $3.5 \mathrm{MHz}$. After three square half-wave cycles, the high-frequency components are all attenuated to less than $1 \mathrm{MHz}$. From the observation of the time-frequency spectrum, only one breakdown happened in this case. Compared with the case of $\mathrm{SF}_{6}$ gap breakdown, the instantaneous frequency component in this case is much lower. Consequently, it is considered that this failure case is caused by a different type of insulation breakdown. As a result, a post insulator of this GIL broke down, leading to this failure case. 


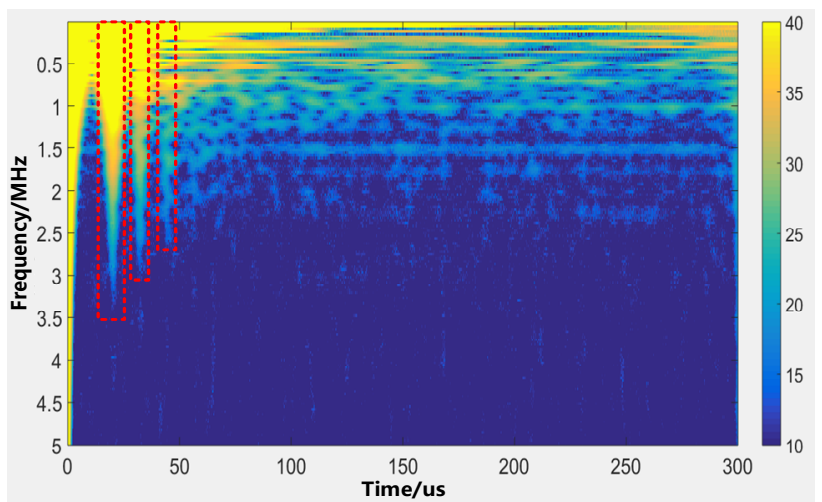

(a)

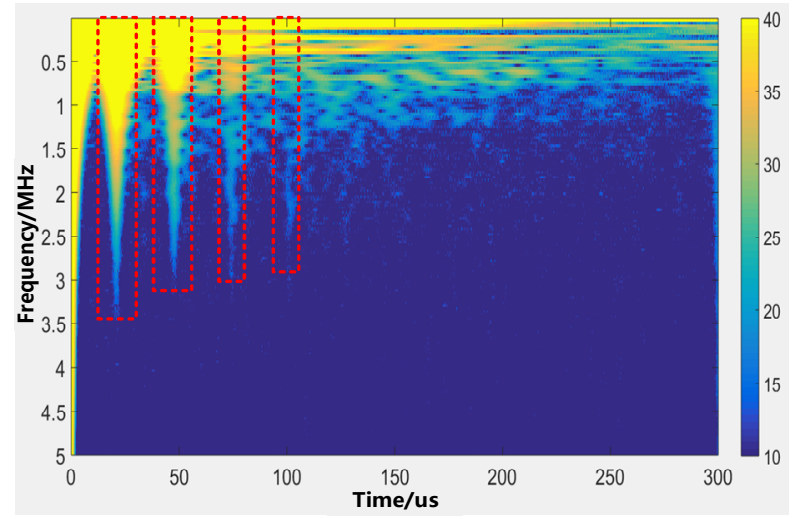

(b)

Figure 9. Time-frequency distributions of the transient voltage excited by flashover in a post insulator of an operating GIL. (a) Spectrum measured by sensor A (south); (b) spectrum measured by sensor B (north).

\subsection{Fault Location of GIL Insulation Flashover during Operation}

Regarding to the case of GIL insulation flashover during operation, the two-terminal TW-based fault location method is applied. The distance between these two UWB voltage sensors installed in this phase of GIL is $5657.7 \mathrm{~m}$. The time difference that the reciprocal TWs arrive at positions of sensor A and B is estimated automatically by identifying the abrupt moments of TW heads. Figure 10 depicts the expanded view of the recorded TW heads, and the time difference $\left(t_{a}-t_{b}\right)$ is about $-7250 \mathrm{~ns}$. The propagation velocity $v$ is approximately $292.9 \mathrm{~m} / \mu \mathrm{s}$. According to Equation (1), the distance $d$ between the location where insulation flashovers and the installation point of sensor A can be derived as follows:

$$
d=\frac{L+\left(t_{a}-t_{b}\right) v}{2}=1767.4 \mathrm{~m}
$$

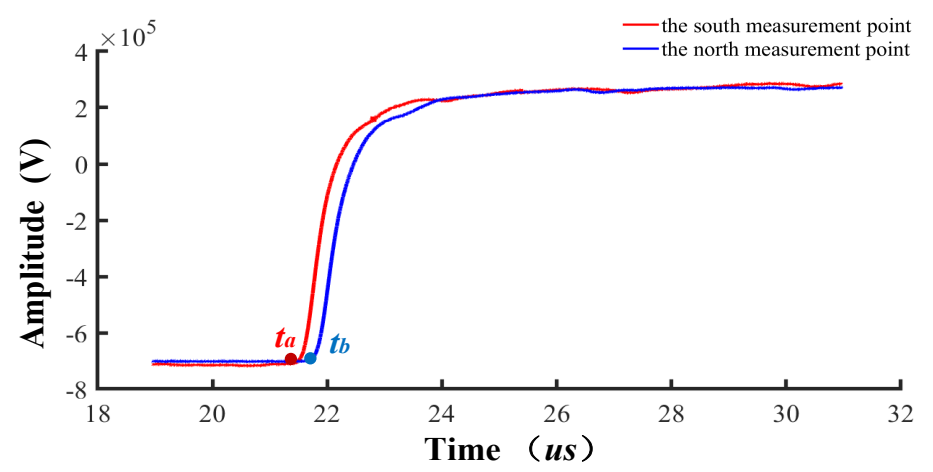

Figure 10. Expanded view of the recorded TW heads.

An inspection was taken after opening the suspected gas chamber of the GIL. A trace of flashover was found near a post insulator of the GIL, as shown in Figure 11. It was $1763.6 \mathrm{~m}$ far away from the installation position of sensor A. Therefore, the location error of this case is $3.8 \mathrm{~m}$. The result satisfies the accuracy of fault location for recognizing the malfunctioning chamber of the $1100 \mathrm{kV}$ GIL tunnels. 


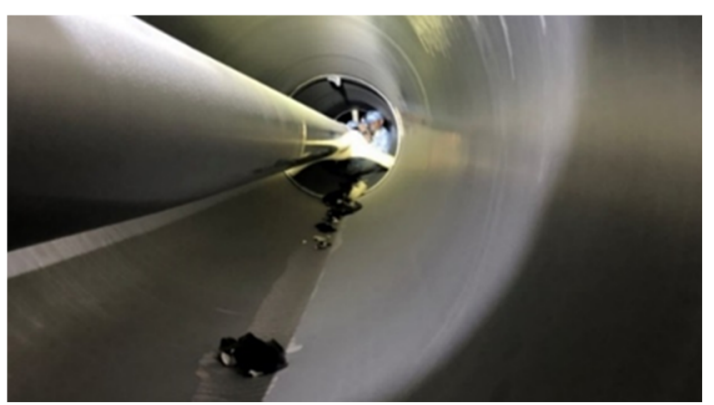

Figure 11. Inspection view of the fault location caused by flashover of a post insulator in GIL.

\section{Conclusions}

In this application paper, a novel transient voltage on-line monitoring system, which is applied in an $\mathrm{kV}$ GIL project, is introduced. The effective measurement bandwidth ranges from $2.1 \mathrm{~Hz}$ to $230 \mathrm{MHz}$. The sampling rate is $250 \mathrm{MS} / \mathrm{s}$, and the analog bandwidth is $100 \mathrm{MHz}$. In order to fast locate the malfunctioning GIL chamber and shorten the maintenance time, a two-terminal TW-based fault location method relying on this monitoring system is developed and implemented. Based on two real-world cases of insulation breakdown captured by the online monitoring system, the characteristics of the transient voltage waveforms in both time domain and time-frequency domain are presented and discussed. The following conclusions are drawn:

(1) The instantaneous frequency of the transient voltage caused by a $\mathrm{SF}_{6}$ gap breakdown case during withstand test exceeds $35 \mathrm{MHz}$, whereas the instantaneous frequency excited by post insulator flashover during operation is around $3.5 \mathrm{MHz}$, which is much lower. Therefore, the characteristics of waveforms could indicate different types of insulation breakdown.

(2) Time-frequency analysis, can be used to estimate whether the GIL has secondary discharge by the time-frequency distribution of transient voltage.

(3) The accuracy of the applied fault location method is validated in the case of insulation flashover during operation. The location error of this case is $3.8 \mathrm{~m}$ and successfully recognizes the malfunctioning chamber.

Author Contributions: Conceptualization, Z.Z. and W.L.; methodology, D.D.; software, Z.Z.; validation, L.H.; formal analysis, Z.Z.; investigation, J.L.; resources, C.B.; writing-original draft preparation, D.D.; writing-review and editing, Z.Z.; visualization, Z.Z.; supervision, W.L.; project administration, L.H.; funding acquisition, C.B. All authors have read and agreed to the published version of the manuscript.

Funding: This research was funded in part by National Natural Science Foundation of China (51977120), National Natural Science Foundation of China (52067021) and Hebei Key Laboratory of Safety Monitoring and Mining Equipment Funding (SM202005).

Conflicts of Interest: The authors declare no conflict of interest.

\section{References}

1. Huang, D.; Shu, Y.; Ruan, J.; Hu, Y. Ultra High Voltage Transmission in China: Developments, Current Status and Future Prospects. Proc. IEEE 2009, 97, 555-583. [CrossRef]

2. Jiao, C.; Ding, D.; Liu, W.; He, L.; Zhang, Z.; Yuan, M. Construction of transient voltage UWB on-line monitoring system in UHV GIL based on capacitive voltage division. In Proceedings of the 2020 IEEE International Conference on High Voltage Engineering and Application (ICHVE), Beijing, China, 6-10 September 2020; pp. 1-4.

3. Koch, H. Gas Insulated Transmission Lines (GIL), 1st ed.; John Wiley \& Sons: Chichester, UK, 2011; p. 4.

4. Koch, H. Basic information on gas insulated transmission lines (GIL). In Proceedings of the 2008 IEEE Power and Energy Society General Meeting-Conversion and Delivery of Electrical Energy in the 21st Century, Pittsburgh, PA, USA, 20-24 July 2008; pp. 1-4.

5. Volcker, O.; Koch, H. Insulation co-ordination for gas-insulated transmission lines (GIL). IEEE Trans. Power Deliv. 2001, 16, 122-130. [CrossRef] 
6. $\quad$ BS EN IEC 62271-204. High-Voltage Switchgear and Controlgear: Part 204. Rigid Gas-Insulated Transmission Lines for Rated Voltage above $52 \mathrm{Kv}$; BSI: London, UK, 2019.

7. IEEE PC37.122.4/DG. December 2012-IEEE Draft Guide for Application and User Guide for Gas-Insulated Transmission Lines (GIL), Rated $72.5 \mathrm{kV}$ and above; IEEE: Piscataway, NJ, USA, 2013; pp. 1-48.

8. Kuroyanagi, Y.; Toya, A.; Hayashi, T.; Araki, T. Construction of $8000 \mathrm{~A}$ class $275 \mathrm{kV}$ gas insulated transmission line. IEEE Trans. Power Deliv. 1990, 5, 14-20. [CrossRef]

9. Hillers, T. Gas insulated transmission lines (GIL): Ready for the real world. In Proceedings of the 2000 IEEE Power Engineering Society Winter Meeting, Singapore, 23-27 January 2000; pp. 575-579.

10. Chen, X.; Hu, Y.; Xin, Y.; Pan, Y.; Liu, F.; Yin, T. Prospect of high voltage long distance compressed-air insulated transmission lines. High Volt. Eng. 2009, 35, 3137-3142. (In Chinese)

11. Benato, R.; Mario, C.D.; Koch, H. High-capability applications of long gas-insulated lines in structures. IEEE Trans. Power Deliv. 2007, 22, 619-626. [CrossRef]

12. Zhou, Y.; Qin, Y.; Du, Q.; Wu, Z.; Ma, J.; Li, X.; Wen, T.; Zhang, Q. Flashover characteristics of basin-type insulator with metallic particles on its surface under standard lightning impulse. In Proceedings of the 2017 IEEE Electrical Insulation Conference (EIC), Baltimore, MD, USA, 11-14 June 2017; pp. 27-54.

13. Guo, Z.; Wu, Z.; Wang, H.; Tian, H.; Liu, L.; Peng, Z.; Li, H.; Wang, Q. Experimental and numerical study on formation of interface separation and interfacial dielectric strength of GIL insulator. IEEE Trans. Dielectr. Electr. Insul. 2019, 26, 1738-1746. [CrossRef]

14. Ueta, G.; Wada, J.; Okabe, S.; Miyashita, M.; Nishida, C.; Kamei, M. Insulation characteristics of epoxy insulator with internal crack-shaped micro-defects-fundamental study on breakdown mechanism. IEEE Trans. Dielectr. Electr. Insul. 2013, 20, 1444-1451. [CrossRef]

15. Ueta, G.; Wada, J.; Okabe, S.; Miyashita, M.; Nishida, C.; Kamei, M. Insulation performance of three types of micro-defects in inner epoxy insulators. IEEE Trans. Dielectr. Electr. Insul. 2012, 19, 947-954. [CrossRef]

16. Okubo, H.; Hoshino, T.; Takahashi, T. Insulation design and on-site testing method for a long distance gas insulated transmission line (GIL). IEEE Electr. Insul. Mag. 1998, 14, 13-22. [CrossRef]

17. Xiong, H.; Jiang, H.; Zhou, B.; Zhou, G. Research on an accident of $500 \mathrm{kV}$ gas insulated transmission line. Appl. Mech. Mater. 2014, 492, 178-181. [CrossRef]

18. Khan, Q.; Refaat, S.S.; Abu-Rub, H.; Toliyat, H.A. Partial discharge detection and diagnosis in gas insulated switchgear: State of the art. IEEE Electr. Insul. Mag. 2019, 35, 16-33. [CrossRef]

19. Poehler, S.; Rudenko, P. Directly buried gas-insulated transmission lines (GIL). In Proceedings of the PES T\&D 2012, Orlando, FL, USA, 7-10 May 2012; pp. 1-5.

20. Li, Y.; Gao, H.; Du, Q.; Qi, X.; Pang, Q.; Zhu, G. A review of single-phase-to-ground fault location methods in distribution networks. In Proceedings of the 2011 4th International Conference on Electric Utility Deregulation and Restructuring and Power Technologies (DRPT), Weihai, China, 6-9 July 2011; pp. 938-943.

21. Baù, M.; Benato, R.; Dambone Sessa, S.; Poli, M.; Quaciari, C. Phase-to-ground fault location methods in unearthed subtransmission networks: A review. In Proceedings of the 2016 AEIT International Annual Conference (AEIT), Capri, Italy, 5-7 October 2016; pp. 1-6.

22. Lopes, F.V.; Lima, P.; Ribeiro, J.P.G.; Honorato, T.R.; Silva, K.M.; Leite, E.J.S.; Neves, W.L.A.; Rocha, G. Practical Methodology for Two-Terminal Traveling Wave-Based Fault Location Eliminating the Need for Line Parameters and Time Synchronization. IEEE Tran. Power Deliv. 2019, 34, 2123-2134. [CrossRef]

23. Du, N.; Xu, W.; Xiang, Z.; Han, Y.; Zhou, P.; Yang, D.; Xiang, C. Research on Key Technical Problem of System Commissioning of Sutong GIL Utility Tunnel Project. In Proceedings of the 2020 5th Asia Conference on Power and Electrical Engineering (ACPEE), Chengdu, China, 4-7 June 2020; pp. 1928-1932.

24. ABB Power Grids Commissions World's First Transmission Line under the Yangtze River. Available online: https://new.abb. com/news/detail/61647/abb-power-grids-commissions-worlds-first-transmission-line-under-the-yangtze-river (accessed on 11 February 2021).

25. Yue, G.; Liu, W.; Chen, W.; Guan, Y.; Li, Z. Development of Full Frequency Bandwidth Measurement of VFTO in UHV GIS. IEEE Trans. Power Deliv. 2013, 28, 2550-2557. 